\title{
Research on PLC-Based Pneumatic Controlling System of Flying Splicer of Web-Fed Offset Presses
}

\author{
Chengwen Chai*, Jifei Cai, Yiming Wang and Shuqin Wu \\ Department of Mechanical Engineering, Beijing Institute of Graphics Communication, Beijing 102600, China
}

\begin{abstract}
Flying splicer is a key component of web-fed offset presses for automatically replacing the exhausting web roll with a new one without stopping the machine. The composition and working principle of pneumatic controlling mechanism for operating the flying splicer is analyzed according to the processing requirements of automatic web alternation. By using the software FluidSim, the pneumatic sequential operation controlling circuitry with multi-cylinders for driving the flying splicer is designed, in which the air cylinders cooperate to accelerate the new reel to the circumferential velocity of the expiring web, paste the adhesive end of the new reel on the expiring web, and cut off the remaining piece of expired web. A system scheme and designing method of the PLC-based pneumatic controlling system suitable for automatic web roll change on high speed offset printing presses is brought out.
\end{abstract}

Keywords: Pneumatic control, flying splicer, web pasting, tension control.

\section{INTRODUCTION}

Flying splicer is an important part of the web-fed offset printing presses which can perform the replacement of the exhausting web roll with the new roll automatically. The web-fed offset printing presses running at the average web speed of $80 \mathrm{~m} / \mathrm{s}$ use up a web roll of 1 meter diameter in approximately 15 minutes, while manual changing of the web roll frequently will result in waste of the raw materials, such as paper, ink and dampening solution, and the decrease of production efficiency. So the flying splicers are usually adopted to change the reels automatically without slowing down the press running speed on the modern printing presses [1].

At present, the main suppliers of flying splicer include MEG Tech, ManRoland, BaldWin, etc. The newest product of MEG could accomplished the reel change at the maximum running speed of $1079 \mathrm{~m} / \mathrm{min}$, which is primarily used for newspaper web-fed offset printing presses and semicommercial web-fed offset printing presses $[2,3]$.

\section{WORK PRINCIPLE OF THE FLYING SPILICER}

The flying splicer is basically composed of reel chucks, reel arm, new reel accelerating mechanism, pasting and cutting off mechanism, and web pre-tension control system [4].

The pre-tension control unit is composed of the dancing roller, drawing rollers and diaphragm brakes, all of which perform the web tension detecting and adjusting $[5,6]$. During the printing process, the tension of the running web may be influenced by many factors, such as the roll shape,

*Address correspondence to this author at the Department of Mechanical Engineering, Beijing Institute of Graphic Communication, Beijing 102600, China; Tel: +86-10-60261464(office), $+86-13426432789$ (Mobile);

Fax: +86-10-60261477;

E-mails: chaichengwen@bigc.edu.cn, chengwen_chai@yahoo.com.cn the printing speed, the substrate performance, and etc. [7]. Once the tension of web fluctuated, the dancing roller would be shifted by the pulling power of the web and the sensor for monitoring the stroke of the dampening cylinder supporting the dancing roller would send the displacement increment to the central control PC $[8,9]$. The adjustment instruction then would be sent to the pneumatic valve, which controls the stroke of the diaphragm besides the reel chuck for modifying the rotating velocity of the roll, subsequently the tension of the web is corrected $[10,11]$. The position alternation of the engaged roll and idle roll is acted by the motor which drives the reel arm to rotate and moves the web roll to the working position.

The reel accelerating mechanism is composed of driving motor, accelerating belt, activating cylinder of the frame, and velocity monitor, all the parts speed up the standstill new reel to match with the running web for automatic web changing. The pasting of the front end of the new reel to the expiring web and the separating of the residual expired web is carried out by the pasting and cutting off mechanism, which is basically composed of pasting arm, foam roller, cutting knife, and their driving pneumatic cylinders [12].

The reel stand usually holds two or three web rolls in the chucks, one of them is unwinding for feeding web into the printing units, and the other ones are ready for substituting the running web as long as the running one is expiring and needs to be changed. Before the idle reel is clamped on the reel stand, its front end is trimmed into $\mathrm{V}$ - or W-shape and stuck to its surface with the double-sided adhesive seal. Along its V-shape edge, the double-sided adhesive tape is also pasted on its surface. The metal or black mark is especially stuck on the front end for monitoring the rotating speed of the roll.

When the capacity of using web roll is enough, as shown in Fig. (1), the reel arm is held at the fixed position to keep the using web roll in the working position. The web is unwinding with the constant tension maintained by the pretension unit and the brake mechanism [13], and the new roll 


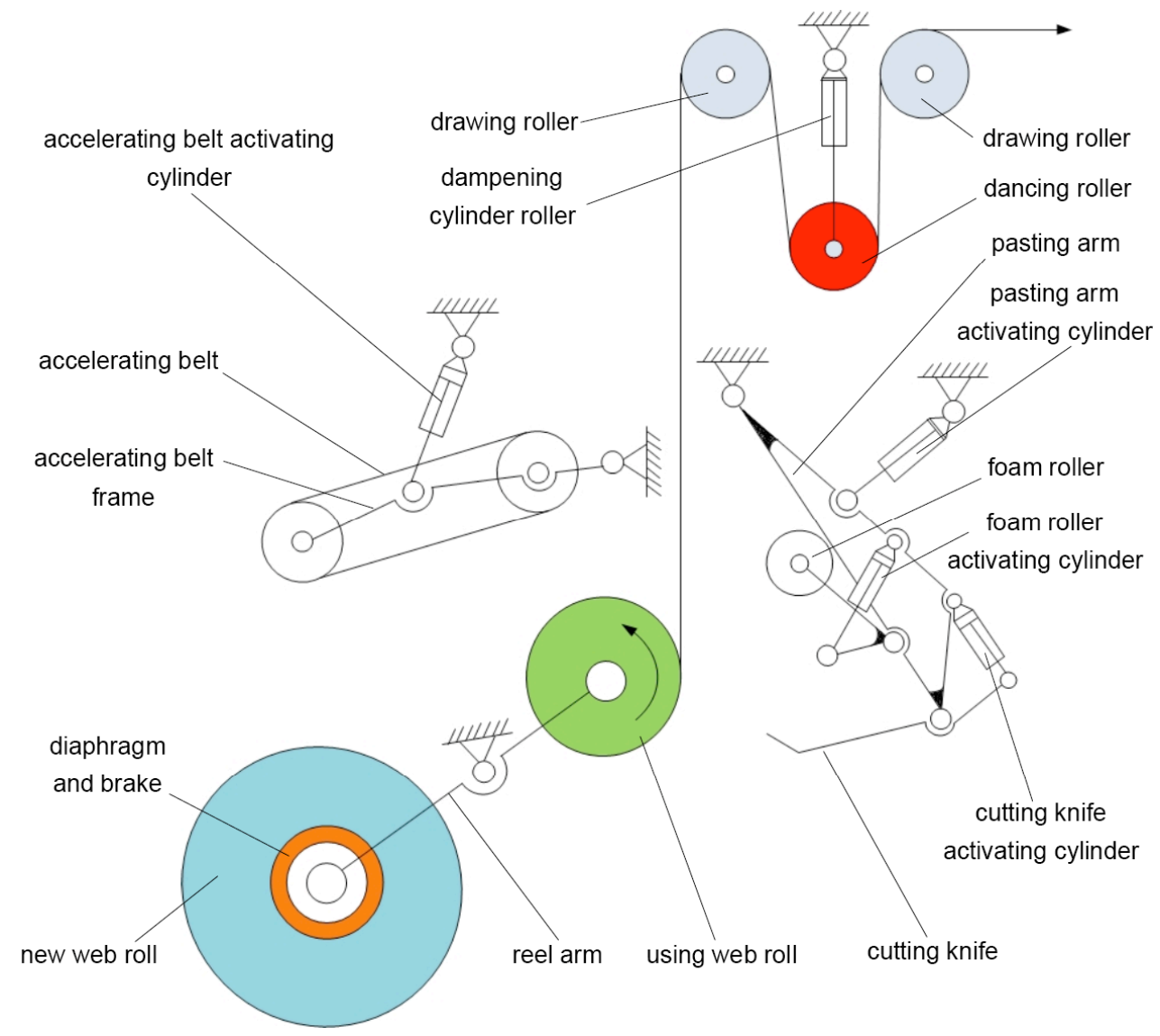

Fig. (1). Flying splicer in the non-working status.

is keeping at the ready position statically. At the same time, the accelerating belt, foam roller and cutting knife are held in the non-working position.

To trigger the reel changing automatically, the web status has to be electronically monitored. Paper consumption is measured continuously by tachogenerators, and the roll diameter is calculated accordingly. Once diameter of the expiring web roll reaches the certain value, the signal for activating the flying splicer to start the changing process is sent to the central console [14]. As shown in Fig. (2), the new roll is firstly moved to the working position by its driving motor and the piston of the accelerating belt activating cylinder get out to push the belt on the surface of the web roll. The driving motor accelerates the belt and the new roll by the friction between it and the belt. The friction coefficient of the belt and the pressure it inflicted on the reel surface must be appropriate not only to accelerate the reel with enough friction power, but to prevent the relative friction between them for avoiding fracturing the roll surface. The angular velocity of the belt wheel is monitored by photoelectric velocity tester which catches the light signal reflected from the black mark sticking on the new web and is added up gradually by the motor drivers. When the surface linear velocity of the new reel is equal to the velocity of the expiring web, the central controlling system will stop accelerating and keep it in the constant velocity [15]. At the same time, the instruction is sent to the direction controlling valve to active the pneumatic cylinder, by which the pasting arm is pushed to the working position for getting ready for

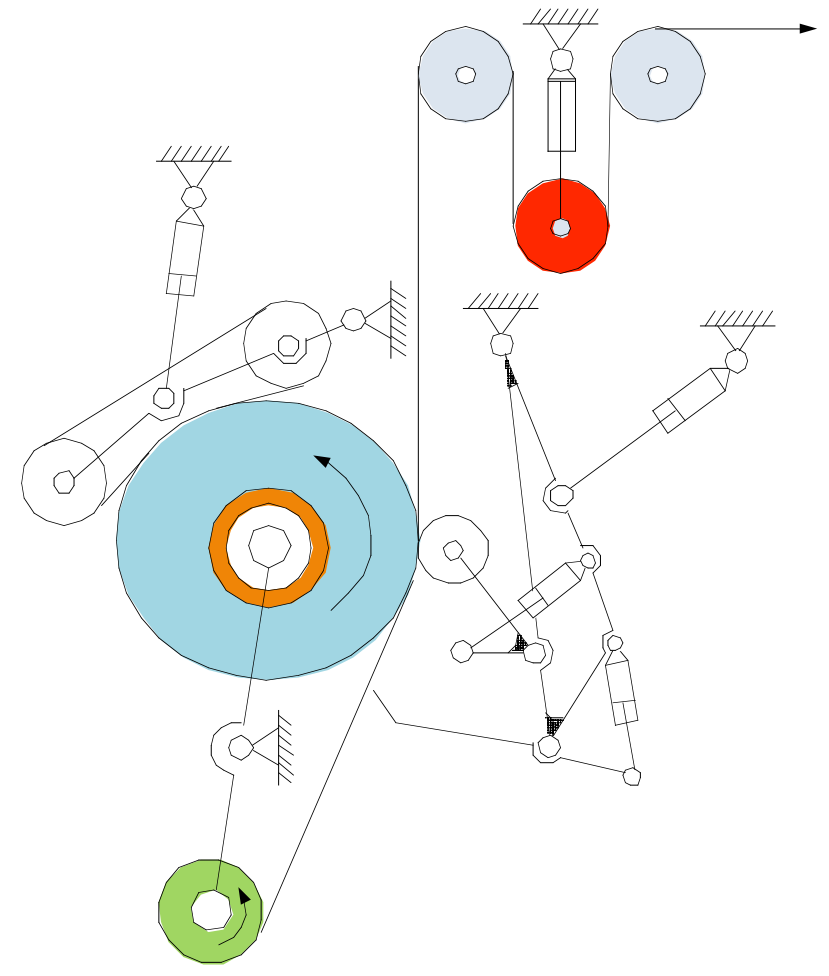

Fig. (2). Flying splicer in the reel changing process.

the pasting. After a delay time for stabilized the pasting arm, the foam roller was driven to press down the expiring web 
on the new reel. Under the pressure imposed by the foam roller, the front head of the new reel with the double-side adhesive is stuck to the expiring web and the pasting seal is broken synchronously. Once the superimposed webs are unwound for some length, the cutting knife swings to pricks the expiring web broken driven by the cutting knife activating cylinder. The foam roller cooperates with the diaphragm brake to tension the web for promising the knife to cut the web successfully. The stroke detector of the cutting knife activating cylinder will send a signal to central control system, once the piston approaches to the detector, immediately the central control system makes all the piston rods retract to their original positions. When all the mechanisms recover their ready status, the reel change is finished completely [16].

During the automatic changing of web rolls, the running speed of the presses are usually reduced in some degree for assuring the success of the web changing, because the tension of the two unwound web would fluctuate intensively at the moment of cutting the expired web apart [17].

\section{COMPOSITION OF THE FLYING SPLICER CONTROLLING SYSTEM}

The control system of the flying splicer aims to direct all the sub-mechanisms to change the web automatically though synergetic control [18]. Its composition is shown in Fig. (3). During the change process, the important parameters, such as the diameter and rotation speed of web roll, tension and speed of web, the stroke of all the pneumatic cylinders, speed of driving motors and braking torque are monitored through the sensors and detectors and fed back to the central control system. The suitable signals trigger the central control system to send constructions to the corresponding mechanisms, such as electric devices, motors and pneumatic cylinders, which carry out the setting motions according to the certain rules and sequence to finish the alternation of the web rolls $[19,20]$.
All modules dominated by the central control system feed the signals back and achieve constructions to drive their actuators to carry out the corresponding motion, as shown in Fig. (4).

The forwarding velocity of the using web and the rotating velocity of the web reel are detected by the sensors, by which the diameter of the using web roll is calculated. Once the diameter of the using roll is equal to the setting value, the web changing process would be triggered. The reel arm is driven by the motor and its decelerator to bring the reel to working position, the position sensors promises the web roll to stop at the accurate place $[21,22]$. All the sequence motion and stroke control of the pneumatic cylinders are carried out by the cooperation of the stroke switches and their direction control valves through the central PLC control module [23, 24].

\section{DESIGN OF PNEUMATIC CONTROL SYSTEM OF FLYING SPLICER}

The most important actions of automatic web change, like accelerating the new reel, pasting and cutting the expired web off are carried out by the pneumatic cylinders. The motion stability and accuracy of stroke control are the key factors of the pneumatic system performance which influence the success of web change. Fluctuation of web tension easily happens when the expiring web roll is very small and rotates in high speed, so the pasting of web and cutting off the expired web must be finished in one breath. If the web change isn't done successfully, the web needs to be threaded into the printing units again. In the extreme situation, the separated web would wind on the blanket cylinder or squash into the inking rollers and the paper oddment would be blended with ink and dampening solution, which is very difficult to clean and time wasting. According to the requirement and control principle of web pasting, the pneumatic control system was designed in the software FluidSim [25], which is made up of the suitable electromagnetic

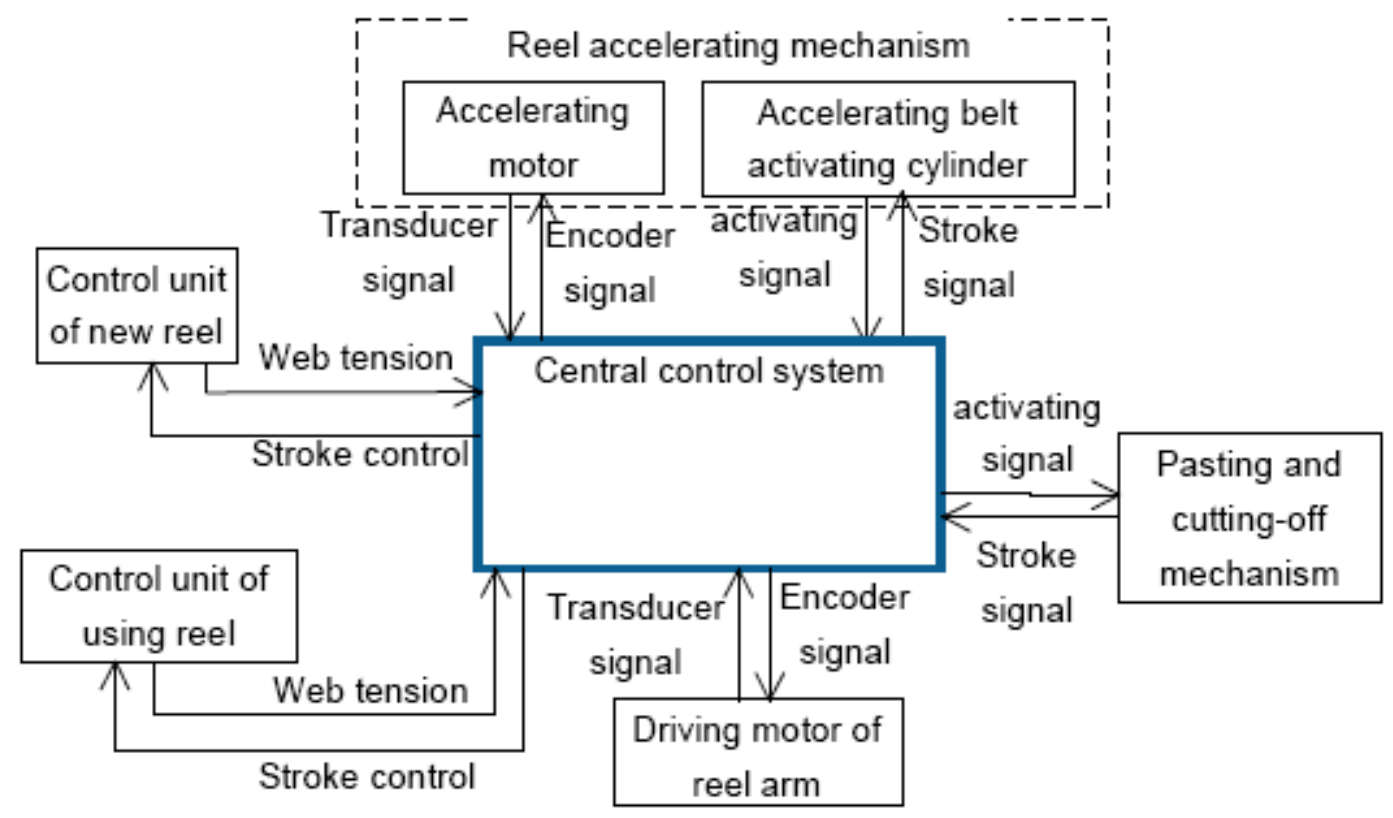

Fig. (3). Control system of flying splicer. 

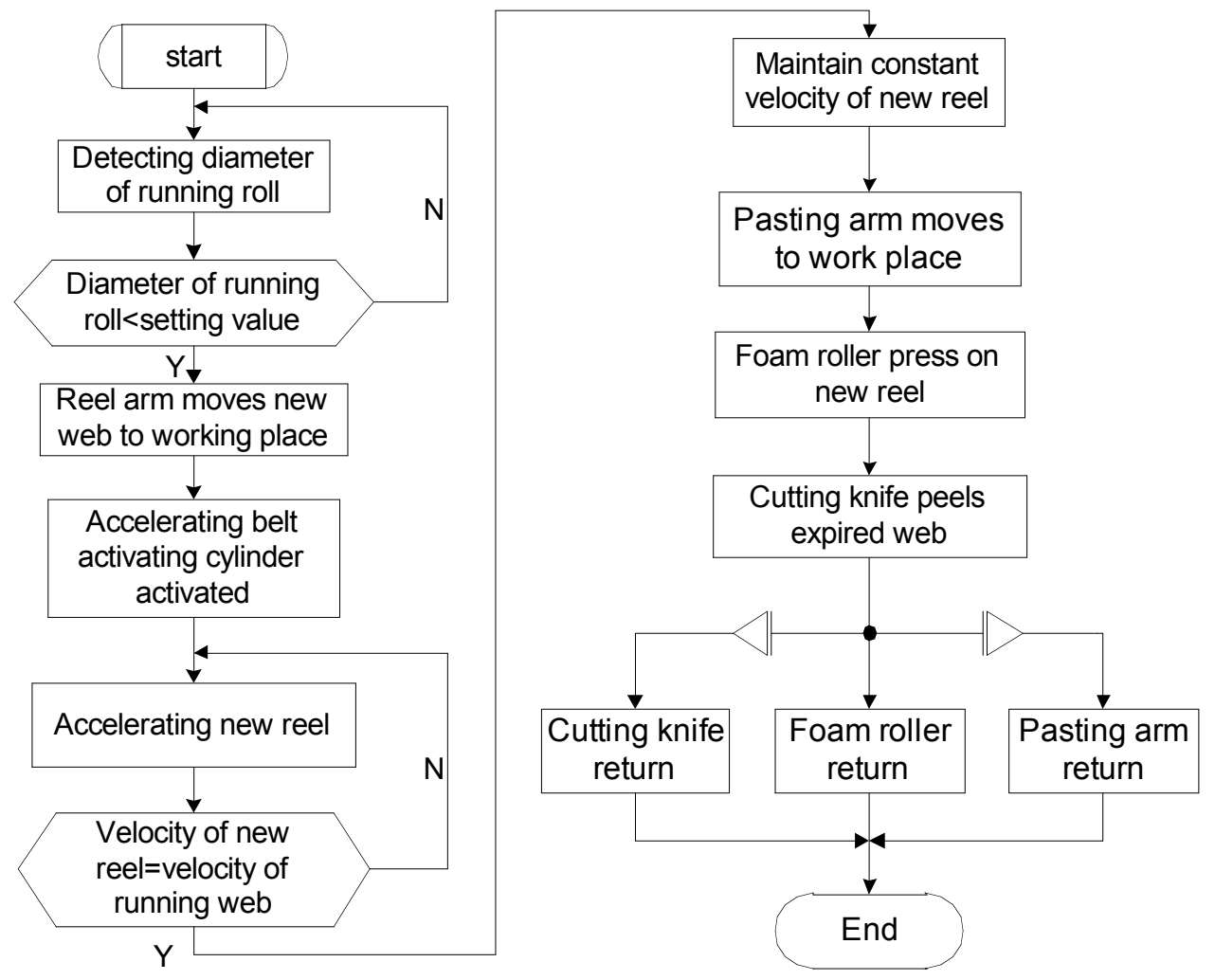

Fig. (4). Working flow chart of flying splicer.

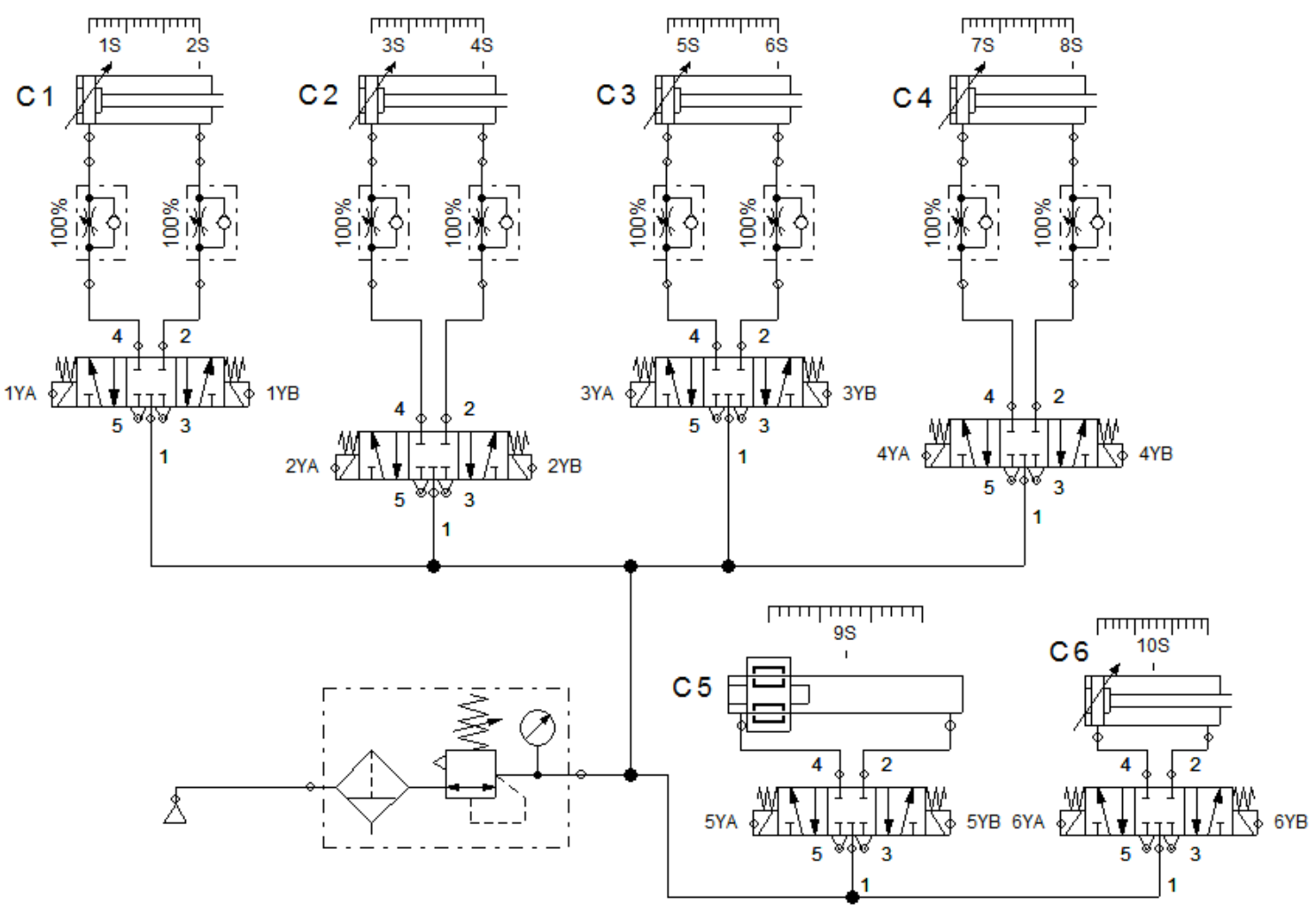

Fig. (5). Pneumatic control system of flying splicer.

direction valves and cylinders, shown in Fig. (5). The system was debugged by the software simulation module.
As shown in Fig. (5), the engaging and disengaging of the accelerating belt is dominated by the cylinder $\mathrm{C} 1$, which 
is activated by the electromagnetic valve 1YA. When the diameter of the using web roll is very small and needs to be changed, the driving motor rotates the reel arm to moves the new web roll to the working position. Once the new reel arrives at the setting position, the position switch will send a signal to trigger the valve 1YA to activate the cylinder to push the belt on the surface of the new reel. The cylinder C2 performs the action of swing the pasting arm to the working position with the foam roller and the cutting knife getting to the ready place. The direction control valve 2 YA is triggered by the comparison result between the forwarding velocity of the using web and the surface linear velocity the accelerated new reel. Only is the velocity of the using web equal to that of the new reel, the compressed air pushes the rod of $\mathrm{C} 2$ out. The cylinder $\mathrm{C} 3$ carries out the motion of swing the foam roller to press the using web on the new reel, which is activated by the delay time signal triggered by the rod of cylinder $\mathrm{C} 2$. The delay time aims to stabilize the pasting arm for promising the success of the change. The cutting of expired web is finished by the cutting knife which is driven by the cylinder $\mathrm{C} 4$. The activating of $\mathrm{C} 4$ is administrated by the direction control valve $4 \mathrm{YA}$, which is trigged by the signal of delay time induced by the rod of cylinder $\mathrm{C} 3$. The front end of the new reel is successfully pasted to the expiring web and left the pasting zone through the delay time. The cutting knife returns immediately when the rod of cylinder $\mathrm{C} 4$ triggers the stroke switch $8 \mathrm{~S}$. As long as the rod of $\mathrm{C} 4$ return to its original position, the stroke switch $7 \mathrm{~S}$ is triggered, which directs the cylinders $\mathrm{C} 3, \mathrm{C} 2$ and $\mathrm{C} 1$ to retreat their rods to the start positions in the non-working status. The diaphragm cylinder C5 collaborates with cylinder C6 which drives the dancing roller to translate in a certain distance to keep the web tension at the constant value along with the web moving process [26].

\section{PROGRAM DESIGN FOR FLYING SPLICER BASED ON GT-DESIGNER CONFIGRATION SOFTWARE}

FX2N PLC was used as the upper control module for the experimental flying splicer and a F940GOT touch screen was connected to the PLC for supplying the humancomputer interaction whose control program was compiled by using the GT-Designer configuration software [27].

The control program of the manipulator based on the PLC was compiled in the software GX-Developer by using the sequential function chart language. The input port X0 was assigned to the manual operating buttons in the touch screen interface, while the input ports from X1 to X12 were allocated to the position sensors and pressure detectors which monitored the piston stroke of the pneumatic cylinders for receiving the feedback signals. The last input port, X12, was assigned to the rotation velocity monitor of the running web roll, by which the trigger signal of starting the web changing process was sent to the PLC control system [28, 29]. Output port $Y 0$ was used to transferring the running information to the display box on the touch screen, and output ports from Y1 to Y14 were all connected to electromagnet coils on the directional control valves for manipulating the pneumatic cylinders motion. The wiring diagram of the PLC module for controlling the flying splicer was shown as Fig. (6).

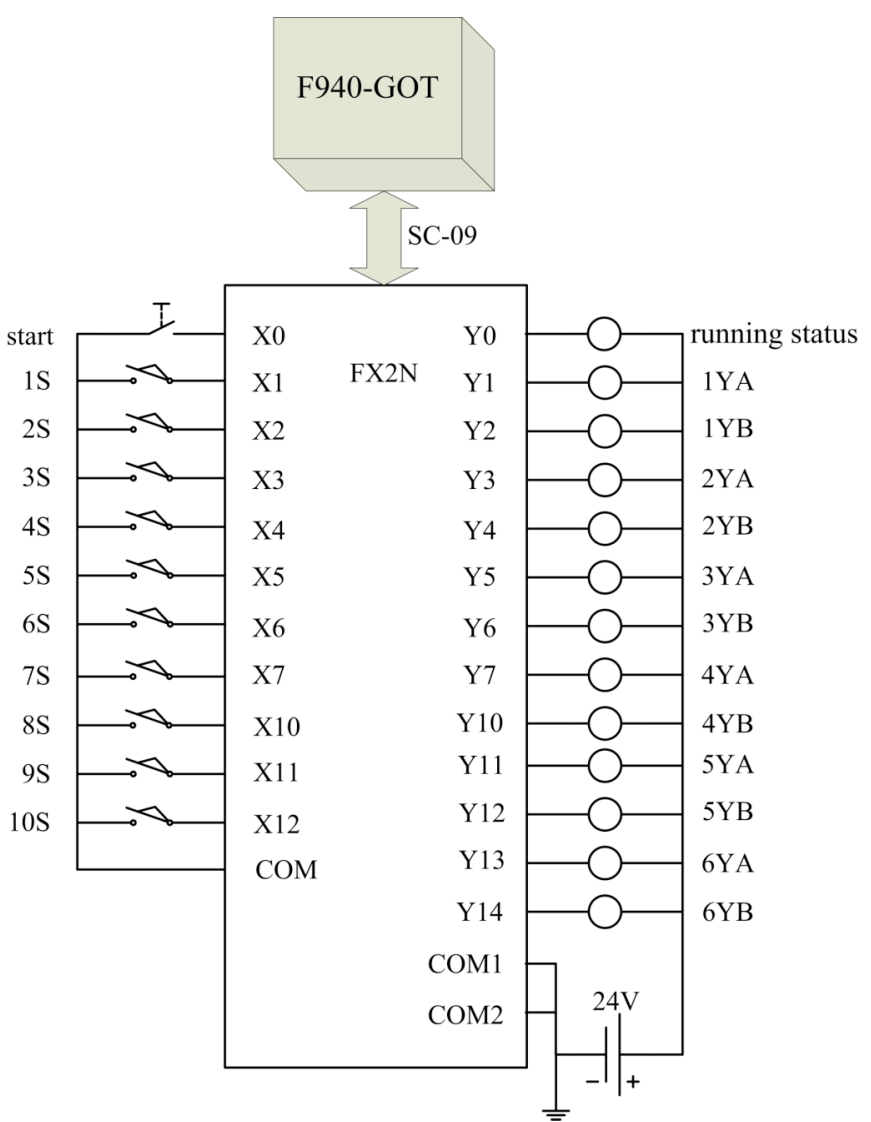

Fig. (6). Wiring diagram of the PLC module for control the manipulator.

\section{CONCLUSION}

(1) The stability of the flying splicer had a key role on guaranteeing the continuous and high efficient productivity of the web-fed offset printing presses.

(2) The flying splicer design scheme was proposed, in which the web change was performed by the collaboration of the pneumatic control system and driving motors without slowing down the running speed of the presses.

(3) The abnormity of the web roll shape could induce the tension oscillation of the web, which would interrupt the pasting process of web rolls. To overcome this problem, the friction imposed on the expiring web by the foam roller and the braking torque put on the web reel shaft by the diaphragm cylinder adjustment were utilized to ensure the pasting motions propitiously with the assistant of the pre-tension unit. Adoption of the pneumatic control system and junior tension control system was the feasible and practical method.

\section{ACKNOWLEDGEMENT}

This work is supported by the Funding Project for Academic Human Resources Development in Institutions of Higher Learning Under the Jurisdiction of Beijing Municipality [PHR(IHLB)](PHR201107144, PXM2011 014223_113518) and the Youth Teacher Fund Project of Beijing Institute of Graphics Communication (b0000009). 


\section{REFERENCES}

[1] Q. Fubin, 2nd ed., Web-fed Offset Printing Press, Beijing: Printing Industry Publisher, 2006.

[2] C. Ralph, "A look at Splicer technologies", GATFworld, vol. 16, no. 2, pp. 1-25, 2004.

[3] S. Yu-qiu, "Pneumatic Control of Web Printing Tape High Speed Automatic Felting", Hydraulic Pneumatic, no. 5, pp. 50-52, 2008.

[4] H. Kipphan, Handbook of Print Media, Berlin: Springer, 2001.

[5] A. Butler, "Automatic splicer for film rolls", VDI Berichte, no. 1719, pp. 101-105, 2002.

[6] D. Christopher "Analysis of paper roll cycle times", GATFworld, vol. 15 , no. 5 , pp. 21-22, 2003.

[7] S. Li, and C. Weifang, "Zero-speed automatic splicer's intelligent remote control system", Ind. Cont. Comput., vol. 22, no. 1, pp. 2122, 2009.

[8] K.C. Lin, and M.-C. Tsai, "Web tension control of a start-up process using observer techniques with friction and inertia compensation", In: 27th Annual Conference of the IEEE Industrial Electronics Society, 2001, pp. 529-534.

[9] X. Zhongjun, M. Yanjing, and L. Yu, "The research of web tension control in the paper machine's drive control", Control Automation, vol. 21, no. 4, pp. 111-112, 2005.

[10] L. Bergman, A. Verikas, and C. Englund, "Modeling and Control of the Web-Fed Offset Newspaper Printing Press", In: Annual Conference of Technical Association of the Graphic Arts, 2003, pp. 27-29.

[11] L. Bong-Ju, K. Sung-Hwan, and K. Chul-Goo, "Analysis of a nonlinear Web-tension control system of a high-speed gravure printing machine", In: SICE-ICASE International Joint Conference, 2006, pp. 893-898.

[12] I.L. Krivts, "Pneumatic actuator with constant velocity mode in reciprocating motion", Int. J. Fluid Power, vol. 9, no. 1, pp. 9-15, 2008.

[13] E.C. Bacharoudis, A. E. Filios, M. D. Mentzos, and D. P. Margaris, "Parametric Study of a Centrifugal Pump Impeller by Varying the Outlet Blade Angle", Open Mech. Eng. J., vol. 2, pp. 75-83, 2008.

[14] G. Junzhong, Y. Junping, "Simulation analysis of pneumatic on-off pressure mechanism on printing press", In: 2010 International Conference on Advances in Materials and Manufacturing Processes, 2010, pp. 1481-1484.

[15] C. Kyung-Hyun, T. Tran-Trung, "On a new approach for gravure/offset printing pressure control algorithm development using the full state feedback controller", In: 2009 IEEE International Symposium on Assembly and Manufacturing, 2009, pp. 88-94.
[16] C. Hong, "The optimal design of sequential engagement and disengagement system in printing press", In: Proceedings of the 2nd International Conference on Modelling and Simulation, 2009, pp. 243-247.

[17] W. Jihong, P. Junsheng, and M. Philip, "Accurate position control of servo pneumatic actuator systems: an application to food packaging", Control Eng. Pract, vol. 7, no. 6, pp. 699-706, 1999.

[18] M. Sorli, S. Pastorelli, "Performance of a pneumatic force controlling servosystem: Influence of valves conductance", Robot. Autonomous Syst., vol. 30, no. 3, pp. 283-300, 2000.

[19] R.T. Schneider, "PLCs, pneumatics and vacuum produce highspeed packaging", Hydraulics Pneumatics, vol. 53, no. 9, pp. 2, 2000.

[20] B. Carlos, L. Albertoand, and G. David, "Dynamic study of stacked packaging units by operational modal analysis", Packaging Technol. Sci., vol. 23, no. 3, pp. 121-133, 2010.

[21] Y.W. Post, H.J. van Oostveen, and A.J. van der Weiden, "Modelling of a controlled pneumatic swing-plug train door", In: Proceedings of the Institution of Mechanical Engineers, 1995, pp. 87-92.

[22] Z. Chong, and Z. Guo-Sheng, "The online infrared pneumatic ordered arrangement for capsules in aluminum-plastic packaging machine", In: International Conference on Computer, Mechatronics, Control Electronic Eng., 2010, pp. 304-306.

[23] M.A. Selver, A. Olcay, and A. Fikret, "An automated industrial conveyor belt system using image processing and hierarchical clustering for classifying marble slabs", Robot. Comput. Integr. Manuf., vol. 27, no. 1, pp. 164-177, 2011.

[24] S. Xiao-Ming, L. Lei, and X. Yun-Qing, "Automatic placing and removing manipulator of the workpiece on stretcher based on electric-pneumatic control and PLC control", In: 6th China-Japan International Conference on Mechatronics, 2010, pp. 5-8.

[25] L. Jian, and L. Yuan-Jun, "Control of testing device based on FluidSIM-P", In: International Conference on Frontiers of Manufacturing and Design Science, 2010, pp. 3702-3705.

[26] X. Jun, and M. Wen, "A PLC-based control system in wheelset disassembly machine", In: International Conference on Computing, Control and Industrial Engineering, 2010, pp. 99-102.

[27] M. Muntaser, A. Mohammed, I. Al-Khawaldeh and H. Al-Mujafet, "Pneumatic, PLC controlled, automotive gear shifting mechanism", Res. J. Appl. Sci. Eng. Technol., vol. 2, no. 3, pp. 245-251.

[28] F. Hui, and T. Wei, "Research and design of AC winder control system", In: 2nd IEEE International Conference on Information Management and Engineering, 2010, pp. 50-52.

[29] J.I. Borislav, and Z.B. Milan, "Realization of rewinder with a reduced number of sensors", IEEE Trans. Indust. Electron, vol. 57, no. 8 , pp. 2797-2806. 